\title{
"Quando você é excluída, você faz o seu"1: mulheres e skate no Brasil *
}

\author{
Márcia Luiza Machado Figueira" \\ Silvana Vilodre Goellner***
}

\section{Resumo}

Fundamentado nos estudos feministas e de gênero, este artigo analisa os modos através dos quais skatistas constroem seus lugares de sujeitos no universo de tal esporte. Foram analisados documentos de diferentes naturezas, os quais possibilitaram identificar que o skate é atravessado por relações de poder, promovendo oportunidades e sociabilidades distintas para homens e mulheres. Em função dessa diferenciação, as mulheres construíram espaços, práticas e discursos tornando visível não só a sua presença, mas, sobretudo, a própria presença dessa modalidade esportiva no Brasil.

Palavras-chave: Skate, Gênero, Esporte.

${ }^{1}$ Expressão utilizada pela skatista Karen Jones em entrevista concedida por telefone a uma das autoras em $1^{\circ}$ de dezembro de 2007.

" Recebido para publicação em 2 de maio de 2011, aceito em 30 de agosto de 2012.

*** Prefeitura Municipal de Porto Alegre. Grupo de Estudos sobre Cultura e Corpo (UFRGS).marluafig@gmail.com

${ }^{* * *}$ Universidade Federal do Rio Grande do Sul. Grupo de Estudos sobre Cultura e Corpo (UFRGS).vilodre@gmail.com

cadernos pagu (41), julho-dezembro de 2013:239-264. 
"Quando você é excluída, você faz o seu"

When You Are Excluded, You do Your Own: Women and Skate in Brazil

\begin{abstract}
Grounded on Feminist Studies and Gender Studies, this research analyses the ways through which skaters have constructed their places as subjects in this sport universe. The analysis of different kinds of documents has led us to identify skateboarding as being crossed by power relations, which foster distinct opportunities and sociability for men and women. Due to this differentiation, women built places, discourses and practices not only making their presence visible but especially the existence of this sport in Brazil.
\end{abstract}

Key Words: Skate, Gender, Sport. 
Identificado como uma modalidade vinculada ao que se denomina esportes radicais, o skate incorpora representações $e$ valores cujos modos de acontecer são ressignificados pelos sujeitos que o praticam nos contextos específicos onde praticam. Presentifica-se, portanto, como um campo de disputa cuja valorização, visibilidade e significação decorrem não apenas de sua prática, mas também dos processos que o constituem.

Considerando que o skate é representado como uma prática culturalmente associada ao universo masculino mais que ao feminino, este texto analisa algumas estratégias adotadas por skatistas brasileiras para produzirem sua visibilidade e se posicionarem como sujeitos dessa prática que, não raras vezes, as invisibiliza.

As análises aqui desenvolvidas encontram sua ancoragem teórica e metodológica em vertentes pós-estruturalistas dos estudos feministas e de gênero. Apoiadas nesses campos teóricos, partimos do pressuposto de que as produções discursivas que circulam em torno do skate produzem aquilo que nomeiam ou que deixam de mencionar. Em outras palavras: a escassez de referências sobre a existência de mulheres praticantes desse esporte não implica afirmar sua ausência. As fontes aqui revisitadas indicam que, desde os primórdios desse esporte, elas vêm protagonizando diferentes formas de vivenciá-lo, não apenas como atletas da modalidade, mas, ainda, como produtoras de informações que promoveram seu reconhecimento $e$ sua visibilidade dentro do cenário dos esportes radicais no Brasil.

Para desconstruir a representação ${ }^{2}$ de que o skate é um esporte para homens, investimos na busca de fontes que permitissem localizar a presença das mulheres no entorno dessa

\footnotetext{
2 Consoante à perspectiva teórica desta pesquisa, por representação entende-se "a produção de significados através da linguagem" (Hall, 1997:16). Não é, portanto, um reflexo daquilo que vemos. É uma construção que envolve as práticas de significação e os sistemas simbólicos através dos quais os significados são construídos. Envolve relações de poder: "poder de nomear, de descrever, de classificar, de diferenciar; o poder de definir, quem está incluído e quem está excluído" (Meyer, 1998:21).
} 
"Quando você é excluída, você faz o seu"

prática. Nesse sentido, constituiu-se como fonte privilegiada de análise o site Skate para Meninas, fundamentalmente pela variedade de informações que colocou em circulação. A partir desse site, foi possível identificar uma série de fontes que narravam, de forma fragmentária, acontecimentos relacionados ao skate praticado por mulheres brasileiras. Destacaram-se, então, outros sites ${ }^{3}$, blogs $^{4}$, reportagens isoladas em revistas esportivas ${ }^{5}$, publicações criadas por mulheres skatistas ${ }^{6}$, documentação referente à organização de campeonatos, circuitos, tours, oficinas, entre outros eventos. A eleição e a análise dessas fontes de origem bastante distintas foram realizadas tendo como eixo norteador aspectos relacionados à presença das mulheres no skate, não no sentido de desenvolver uma pesquisa historiográfica e, sim, de colocar em suspeição aquelas narrativas que, ao se referirem ao skate no Brasil, raramente registram as mulheres, suas conquistas, frustrações e vivências nesse esporte.

Tomando como inspiração o método indiciário, tal qual propõe Ginzburg (2003), vasculhamos nessas reminiscências detalhes e minúcias para trilhar, mesmo que de forma descontínua, alguns vestígios que contassem algo sobre o skate feminino no Brasil, dado que, oficialmente, ele parece inexistir. ${ }^{7}$ Optamos por esse percurso metodológico por entendermos que todas as práticas, as representações, as ideias e os discursos assim

${ }^{3}$ Mary Jane: <http://www.maryjane.com.br/pags/index.asp?include=home>; Garotas no Comando: <http://www.garotasnocomando.com.br/garotasold/index.htm>; Associação Brasileira de Skate Feminino: <http://www.absfe.blogspot.com>; entre outros.

${ }^{4}$ Destacam-se os blogs Unidas pelo Carrinho e Leni Cobra, entre outros.

${ }^{5}$ As revistas Tribo Skate e 100\%Skate, com destaque para os dois encartes, intitulados 100\% SkateGirls, publicados em 2001 e 2002.

${ }^{6}$ Destaque para a revista Check it Out.

7 O site da Confederação Brasileira de Skate menciona raríssimos dados sobre o skate feminino. No link sobre a história da modalidade no Brasil, nenhuma referência é feita à participação das mulheres. Site: <http://www.cbsk.com.br/pags/historia_brasil.htm>. Acesso em: 21 abr. 2011. 
o são porque foram produzidos (dessa forma e não de outra qualquer) em determinado tempo, cultura e sociedade. Portanto não se revela como a verdade, mas uma produção discursiva que a cria $e$ a institui.

Para Ginzburg (2003), a prática indiciária não busca retirar conclusões gerais sobre a humanidade, dada a impossibilidade de tal intento; busca, ao contrário, retirar conclusões de determinada cultura em determinado período histórico. $\mathrm{O}$ autor desenvolve tal argumentação a partir da articulação que faz entre as técnicas de trabalho empreendidas por Giovanni Morelli, Freud e Sherlock Holmes, nas quais observa algumas semelhanças relacionadas, principalmente, à observação do detalhe.

No "método morelliano" - desenvolvido para atribuir autoria a obras de arte, buscando encontrar falsificações identifica que o autor, em vez de observar os quadros a partir de suas características mais óbvias, centra sua atenção em características mais negligenciáveis, tais como alguns detalhes nas orelhas e nos dedos. No pensamento de Freud, aponta serem as pequenas atitudes aquelas que revelam a personalidade do indivíduo, de modo que seria capaz de dissimular seus traços em suas grandes ações, mas dificilmente os faria em suas atitudes mais corriqueiras. Em Sherlock Holmes, personagem criado por Conan Doyle, considera que é a partir da observação minuciosa de pequenos indícios que o detetive identifica a autoria de crimes. Em síntese: tais métodos perscrutam as minúcias e, a partir delas, propõem interpretações.

Inspirado nessas pistas, Ginzburg entende que a construção da narrativa historiográfica é caracterizada pela capacidade de

a partir de dados negligenciáveis, remontar a realidade complexa não experimentável diretamente. Pode-se acrescentar que esses dados são sempre dispostos pelo observador de modo tal a dar lugar a uma sequência narrativa (Ginzburg, 2003:152). 
O trabalho com indícios, portanto, pressupõe alguns procedimentos de investigação que dizem respeito aos critérios de identificação dos dados a serem observados como representativos do que se quer tomar como a singularidade que revela, assim, como um rigor metodológico, entendido aqui de modo distinto dos paradigmas investigativos centrados em procedimentos experimentais. No interior desse "rigor flexível" (Ginzburg, 2003), são importantes elementos como, por exemplo, a intuição do investigador na observação do singular, do idiossincrático, bem como a sua capacidade de formular hipóteses explicativas.

A participação das mulheres no skate brasileiro é analisada nessa perspectiva, na medida em que mapeamos registros marginais que, ao serem observados no detalhe, tornaram-se reveladores de histórias nem sempre reconhecidas ou mesmo narradas.

\section{Skate no Brasil: um território generificado e generificador}

A prática do skate no Brasil data de meados da década de 1960. No entanto sua disseminação se deu a partir do final dos anos 1970, com a construção dos skateparks e a realização dos primeiros circuitos e campeonatos. ${ }^{8}$ Apesar de já ser consolidada e reconhecida como uma prática esportiva urbana, muitas das narrativas que reportam à sua existência nem sempre nomeiam alguns grupos sociais e sujeitos que dele participam. Ao relacionarmos essa afirmação com questões de gênero, apontamos para distinções existentes, no Brasil, entre a visibilidade conferida a mulheres e a homens no entorno da sua prática. A adesão e a permanência de sujeitos do sexo masculino nesse esporte são de tal modo naturalizadas que não precisam ser ditas, nomeadas ou chamadas a ver. Por essa razão, os discursos que circulam em diferentes artefatos culturais referem-se, sobretudo, a eles - os skatistas, atletas, espectadores, comentaristas, dirigentes e editores como os protagonistas desse esporte.

8 Sobre esse tema, ler Britto (2000) e Bittencourt (2005). 
Essa representação não está distante de várias narrativas que buscam explicitar as origens do esporte no Brasil e no mundo. Se nos rastros da história do esporte encontramos vestígios que sugerem aos homens as modalidades que solicitem força, velocidade, resistência e potencialização muscular, para as mulheres indicam-se práticas que exercitem flexibilidade, agilidade, leveza e suavidade nos gestos corporais. Segundo Adelman (2006), o esporte é um espaço permeado por intensos conflitos em torno do que pode ou deve fazer um corpo masculino e um corpo feminino, uma vez que esse campo também produz e faz circular determinadas representações de masculinidade $e$ feminilidade que são inscritas nos corpos, marcando a pele e os modos de viver de homens e mulheres. Mostra-se, portanto, como um espaço generificado e generificador, não porque seja assim em sua essência, mas porque é uma construção cultural à qual se agregam discursos, valores e práticas que acabam marcando nos corpos representações de feminilidades e masculinidades, que definem, também, posições sociais.

Ao analisar as formas como se constroem as posições de sujeito no interior de uma cultura, Louro (2005) tece algumas reflexões que podem ser aproximadas da análise que desenvolvemos acerca da hierarquização de gênero que se estabelece no skate. Quando explicita que cada cultura define o que é considerado o normal, o diferente e o excêntrico no que se refere ao gênero $e$ à sexualidade, evidencia que a posição central é considerada como a posição não problemática, a partir da qual todas as outras posições de sujeito, de alguma forma, estão ligadas e subordinadas e em função da qual todos os diferentes são nomeados.

Aproximando essa argumentação ao campo do skate brasileiro, é notória a posição de centro ocupada pelos homens, considerados como os referentes. As mulheres são as outras, estão à margem e, por assim ser, disputam posições e poderes, pois, como qualquer produto da cultura, o skate é um território pleno de embates, inclusive de gênero. Um espaço que demanda disputas por significação, visibilidade e, até mesmo, existência. 
Problematizar essa hierarquização significa desconstruir os discursos que afirmam o lugar privilegiado de quem está no centro. Afinal, é exatamente a recitação contínua desse lugar como posição central que "nos faz acreditar em sua universalidade e permanência, nos ajuda a esquecer seu caráter construído e nos leva a lhe conceder a aparência natural" (Louro, 2005:44).

Essa naturalização pode ser identificada na quase ausência, no Brasil, de registros que mencionem a participação das mulheres no universo cultural do skate, ainda que tenhamos indícios de que, desde o princípio, elas estivessem presentes. Para tentar capturar esse movimento, buscamos mapear algumas fontes nas quais pudéssemos encontrar vestígios acerca de seu protagonismo. De imediato, percebemos que, em sua grande maioria, as informações sobre o skate feminino eram produzidas pelas próprias skatistas. Ao analisarmos várias dessas fontes, identificamos que algumas estratégias adotadas pelas mulheres foram determinantes para a sua visibilidade na modalidade e, inclusive, para a estruturação do skate feminino no Brasil, pois essa atuação acabou por promover a realização de campeonatos, a existência de premiações, a busca dos patrocínios, a adesão de novas participantes, a visibilidade na mídia, enfim, uma série de situações que possibilitou a sua emergência.

\section{Estratégias para se fazer ver}

Dentre as várias ações empreendidas em prol da visibilidade do skate praticado por mulheres no Brasil, algumas se mostraram como basilares, na medida em que possibilitaram a emergência de outras. Nesse sentido tornou-se fonte privilegiada de informação o site Skate para Meninas ${ }^{9}$, um desencadeador de várias ações protagonizadas pelas skatistas, seja pelo que publica, seja pelas inúmeras ações que a partir dele foram implementadas.

${ }_{9}$ Criado em 2002 pela skatista paulista Evelyn Leine, que é a webmaster desde então. Mais informações em: <http://www.skateparameninas.com.br/index.php>. Acesso em: 29 abr. 2011. 
Além de uma série de informações disponibilizadas nos seus diferentes links, o Skate para Menina, desde seu início, tem promovido iniciativas que extrapolam os limites do ciberespaço: organização de encontros, campeonatos, exposições, venda de produtos, realização de oficinas pedagógicas, desenvolvimento de ações sociais, entre outras. Uma delas foi a criação do blog denominado Unidas pelo Carrinho. Nele, garotas de diferentes lugares do Brasil começaram a se comunicar motivadas pelo interesse comum pelo skate, conforme podemos identificar em uma mensagem postada por uma de suas criadoras:

O Blog Unidas Pelo Carrinho surgiu de uma conversa entre
amigas skatistas pelo ICQ. Detalhe que nenhuma se
conhece pessoalmente, pois cada uma é de um lugar do
Brasil. Todas tinham a mesma vontade: divulgar mais o
carrinho entre as meninas do Brasil e do mundo, além de
sempre apoiar uma a outra. Então: por que não fazer um
blog onde possamos falar diariamente sobre nossas
dificuldades, dar pequenas dicas, falar de manobras, marcas
de skate, preconceito e diversos outros assuntos que cercam
nossas vidas? Demorou um pouco pra sair do papel, mas
estamos aí cada dia mais forte (Como Surgimos, 2002:s/p).

Ao analisar o blog e algumas de suas mensagens, é possível perceber que, através dele, as skatistas encontraram uma estratégia de colocar em movimento suas ideias e seus interesses, compartilhando formas de se posicionar no esporte. A própria denominação Unidas pelo Carrinho já remete a uma ideia de comunidade, de pertencimento, de engajamento a um grupo, a uma causa, a uma intenção, nesse caso, o skate.

Para além do blog, a fundação da Associação Brasileira de Skate Feminino (ABSF) foi determinante para a divulgação e a estruturação da modalidade, porque, além de representar um passo na institucionalização da modalidade, criou uma regulamentação específica para a participação em circuitos e campeonatos, 
conectando o skate feminino a instituições representativas do esporte nacional, como confederações e federações.

Afora a preocupação com a profissionalização da modalidade, a criação da associação significou, também, uma reação ao silenciamento sobre a presença das mulheres nas instituições oficiais do skate, que as desconsideravam quase por completo. A Confederação Brasileira de Skate, cuja finalidade é divulgar, desenvolver, difundir e organizar o esporte, além de representá-lo perante os poderes públicos (municipal, estadual e federal) e a sociedade organizada (empresas, ONGs, fundações, associações e federações), nunca teve uma mulher compondo seu quadro dirigente, nem sequer registrou sua história nos seus documentos oficiais. No seu site não há referência à existência do skate feminino $e$, apenas muito recentemente, incluiu o nome de algumas atletas vitoriosas em campeonatos nacionais e internacionais.

Ao analisarmos esse silenciamento, dialogamos com Foucault (2003), quando indica que o poder e o saber são produtivos. No caso da Confederação Brasileira de Skate, a pouca menção que confere às skatistas brasileiras e o não empenho em realizar ações que consolidem essa modalidade (apesar de mencionar que existem competidoras) tornaram-se produtivos pela própria ausência: incitaram a ação das skatistas em prol da criação de um espaço institucionalizado que atuasse nesse sentido. Assim, a estruturação da ABSF traduziu-se como a reafirmação de um espaço de mulheres, um espaço institucionalizado capaz de fornecer melhores condições para que pudessem alcançar legitimidade e reconhecimento. Em outras palavras: foi a criação e a consolidação de uma estrutura que permite a realização sistemática de circuitos e competições, a garantia de patrocínio para as atletas, a profusão de escolinhas pedagógicas, as premiações dos campeonatos de forma igualitária àquelas conferidas aos atletas homens, a possibilidade de realizar cursos para melhorar a gestualidade técnica, enfim, uma série de ações que poderiam, minimamente, garantir a existência do esporte com uma boa qualidade técnica e estrutural. 
As criações do site, do blog e da ABSF devem ser compreendidas nesse contexto. Para as skatistas, não bastava apenas adentrar o espaço cultural do skate; nele desejavam inscrever sua marca, sua singularidade, ou ainda, fazerem-se ver. Ao cruzar várias fontes de pesquisa, percebemos que essas ações tiverem repercussão em outros espaços que não apenas naqueles por elas liderados.

Cauê Muraro, um dos editores da revista $100 \%$ Skate, ao assinar o editorial da segunda edição do encarte 100\%Skate Girl, destacou que as skatistas marcaram o cenário nacional a partir de diferentes ações, entre elas a criação da ABSF. Vejamos:

Nove meses já se passaram desde o lançamento da $100 \%$ SkateGirl e não há como fugir da pergunta. "Teria nosso tão estimado suplemento feminino cumprido o objetivo de atender às exigências - e por que não, carências - das garotas que se atrevem a adentrar o mundo do skate?" Há muito que as meninas ambicionavam um espaço só seu na revista. Pediram, clamaram, reclamaram (e mais uma infinidade de outros verbos). Sobretudo elas ANDARAM de skate. Por isso CONSEGUIRAM. [...] insistiram em andar de skate, em acertar manobras, em correr campeonatos, em evoluir. Até associação elas cuidaram de providenciar a sua. E já dizem por aí que vão promover os seus próprios eventos. Sim, um circuito organizado, quem diria, pela Associação Brasileira de Skate Feminino, ou ABSF se preferir (Muraro, 2002:7).

Ou seja, as skatistas perspectivaram a ABSF tendo em vista a necessidade de tomar para si a organização da modalidade, demarcando sua territorialidade dentro de um contexto que se mostrava composto por diferentes segmentos: atletas, dirigentes, mercado esportivo, patrocinadores, instituições diversas. No entanto, para se fazer ver, era necessário ir mais longe, adentrando também o espaço urbano, deslizando sua presença nas ruas das cidades. Razão pela qual investiram na realização de 
encontros, tours, campeonatos, circuitos, buscando criar outras paisagens nas quais pudessem existir e ser vistas. Nesse sentido, investiram na sua aparição em espaços públicos, tais como ruas, eventos, campeonatos, festas, parques, praças, entre outros. Tal percepção pressupunha, ainda, se apropriar de algumas estruturas, equipamentos e espaços funcionais das cidades, conferindo-lhes outros sentidos e significações.

Uma das primeiras ações desenvolvidas nessa direção foi a realização do $1^{\circ}$ Encontro Unidas pelo Carrinho, que aconteceu em São Paulo, no ano de 2004, com o objetivo de "juntar um monte de meninas para andar de skate" (Leine, 2004:1). Tal evento foi organizado para celebrar um ano da existência do blog Unidas pelo Carrinho e para comemorar o Dia Internacional da Mulher.

Sua realização foi pauta de reportagens em diferentes programas televisivos, revistas e sites esportivos ${ }^{10}$, o que acabou por produzir efeitos bastante positivos para a visibilidade do skate feminino no Brasil. Ao noticiar esse campeonato, diferentes segmentos midiáticos admitiam, ainda que sutilmente, a percepção de que, no Brasil, havia praticantes, atletas e mulheres interessadas e envolvidas com tal modalidade esportiva.

A realização desse encontro parece ter sido pensada para operar nessa perspectiva. Motivo pelo qual não aconteceu de improviso ou naturalmente. Foi fruto da percepção de que, para o skate feminino avançar, era necessário empreender ações coletivas voltadas à mobilização de pessoas identificadas com a causa. Ao avaliar o evento, Alessandra Meduza, uma das suas organizadoras, divulgou os sucessos da iniciativa:

Mulheres em peso, pista literalmente dominada. Foram 42 skategirls, desde feras que disputam os principais circuitos

${ }^{10} \mathrm{O} 1^{\mathrm{O}}$ Encontro Unidas pelo Carrinho foi matéria na Tribo Skate, na seção Lilith, que divulgou o evento tanto no site como na revista impressa (Edição $\mathrm{n}^{\circ}$ 103); nos sites da revista $100 \%$ Skate, do Skate Para Meninas, do Garotas no Comando, do Skate.net e do Terra Noticias. Foi também matéria do programa Zona de Impacto, do canal SporTV, da Rede Globo. 
do país, até meninas que estão começando a andar agora, uma nova safra de skatistas que chegam com muita vontade de andar com estilo próprio, intensidade, agressividade e tudo com muita graça e feminilidade. $\mathrm{O}$ evento além de reunir a mulherada para se divertir serviu para mostrar que o skate feminino é uma realidade. A performance das meninas na pista deixou muito marmanjo de boca aberta (Meduza, 2005:1).

Sua fala evidencia que, mesmo sem nenhum apoio estrutural, diferentes skatistas estavam em ação: profissionais, iniciantes, aspirantes, promotoras de eventos, entre outras. Além disso, a organização desse evento esteve carregada de sentido político, seja porque através desse encontro as skatistas se posicionaram individualmente e envolveram-se com a produção de si, seja porque foi relacionado com o Dia Internacional da Mulher. Ou seja, as skatistas, ao inscreverem esse encontro no universo das celebrações em torno de uma data carregada de simbologias, apropriaram-se de uma tradição e nela também reinscreveram sua história.

Outra estratégia de visibilidade desencadeada foi a realização de tours. O primeiro deles aconteceu no estado de São Paulo, quando percorreram algumas cidades com o propósito de viajar, conhecer outros lugares, andar de skate e divulgá-lo. Em reportagem publicada no site Skate para Meninas, descreveram o tour e publicaram diversas fotos com as skatistas em ação, avaliando essa vivência com as seguintes impressões: "na volta as bagagens estavam cheias de aventuras, experiências, imagens $e$ muita alegria" (Leine, 2005).

Para as skatistas que se envolveram com o tour, essa também foi uma atividade que envolveu aprendizagem técnica. Ao explorarem os picos $^{11}$ de várias cidades, apropriaram-se de diferentes espaços públicos e os ressignificaram, visto que, para esse esporte, ruas, corrimões, escadarias, bancos, calçadas, praças

${ }^{11}$ Picos são locais designados para a prática do skate tais como pistas e praças. 
e parques são promotores de um diálogo entre a carne e o ferro, o cimento, a pedra, o que envolve velocidade, equilíbrio, agilidade e controle corporal.

As trocas de informações e experiências vivenciadas nos tours demandaram outra estratégia de se fazer ver: a criação de modalidades de competição na categoria feminina que eram inexistentes nos campeonatos promovidos pelos órgãos oficiais do esporte. Sua inclusão mostrou-se como um modo de entrar nas competições bem como uma forma de aprimorar a técnica do esporte, de apurar o gesto em busca da melhor manobra, enfim, de se aproximar dos níveis de exigência daquelas provas que só existiam para os homens. Tais investimentos geraram impactos na comunidade do skate, colaborando para que despontassem, em diversas cidades e estados do Brasil, campeonatos que continham na sua programação provas para mulheres. Ou seja, ao protagonizar diferentes ações, as skatistas fizeram o esporte acontecer. $\mathrm{O}$ protagonismo aqui não é entendido apenas como uma aparição cênica; tem outra propriedade. Trata-se de ações coletivas através das quais se constroem a autonomia dos participantes e o envolvimento da coletividade com a ação (Iulianelli, 2003:71). Nesse sentido, talvez a melhor manobra protagonizada pelas skatistas tenha sido o movimento que fizeram não só para divulgar o esporte, mas, sobretudo, para legitimar sua realização.

Alexandre Vianna, presidente da Confederação Brasileira de Skate (CBSK), percebeu essa mobilização e sobre ela emitiu opinião:

A evolução do skate feminino é importante para o esporte porque desmistifica todo aquele rótulo [...] um esporte de ação, só pode ser praticado por homens. É legal ver as meninas se unindo na construção de um espaço e de uma identidade dentro do skate nacional, antigamente isso não acontecia. Hoje $11 \%$ dos praticantes de skate na cidade de São Paulo são mulheres (Vianna, 2004:1).

Embora definisse como importante o que denominou de "evolução do skate feminino", sua fala evidenciou o pouco 
investimento em termos de ação dos órgãos institucionalizados, objetivando melhorar as condições concretas de existência do skate feminino no Brasil. No momento que faz essa declaração, Vianna dirige a instituição máxima que regulamenta a modalidade no Brasil, que estabelece as regras, as normas e o funcionamento de campeonatos e circuitos. Além disso, é o editor da revista $100 \%$ Skate, que é dotada de grande reconhecimento e circulação. $\mathrm{Na}$ rede de poderes que envolvem o skate, está posicionado no lugar de autoridade; integra, com representatividade institucional, a maquinaria que faz funcionar o skate brasileiro, pois está profundamente envolvido nas práticas que organizam e regem esse esporte $e$, por consequência, na produção de discursos $e$ posições de sujeito. Essa afirmação implica dizer que existe um sistema esportivo constituído por uma rede que o organiza e o mantém, cuja existência está atravessada por relações de poder exercidas por diferentes sujeitos. Há, portanto, uma pluralidade de interesses em jogo, que nem sempre estão consoantes às expectativas das e dos atletas e praticantes de skate.

Em função disso, as mulheres, ao criarem estratégias de acesso e permanência nessa prática esportiva, posicionaram-se nesse campo e construíram ações em defesa do direito de praticar esse esporte e nele se realizar. Fizeram ver que o skate não é só para homens e que representações que operam em torno dessa afirmação são de ordens política e cultural, e não decorrentes de uma suposta diferenciação oriunda da distinta anatomia de seus corpos.

\section{O skate não tem sexo}

Skate para Meninas! Ao buscarem, recorrentemente, fazer circular essa afirmação, as skatistas estão explicitando que as capacidades e as habilidades necessárias à sua prática ultrapassam o dimorfismo sexual. Tal reafirmação só faz sentido porque, junto às pistas, aos eventos, aos espaços virtuais e aos encontros, deslizam representações de gênero que percebem o skate como uma prática 
esportiva mais direcionada ao masculino; ou melhor, a uma representação de masculinidade que celebra a aventura, a ousadia, o risco, o destemor, a virilidade, portanto, não sendo relacionada às mulheres. Ao analisarmos o tom do editorial do primeiro encarte 100\%SkateGirl, nos deparamos com esta representação:

As diferenças físicas existem, mas o skate nunca foi um esporte apenas para homens. A questão é que as características do esporte sempre atraíram uma maioria de praticantes deste sexo. Hoje esse perfil está mudando. É cada vez maior o número de mulheres que se aventuram no skate. É inegável que o preconceito existe, mas está perdendo a força ou pelo menos mudando de forma $e$ restringindo-se à opinião individual [...] para isso muitas meninas tiveram que dar exemplo durante anos, passar por cima de "tiradinhas" para consolidar a imagem da menina skatista. A $100 \%$ deparou-se com a necessidade de criar um novo espaço. Não somos meninas mostrando moda ou falando de garotos. Somos skatistas falando sobre e para skatistas. Lutamos juntos contra preconceito e uma maior exposição de pessoas que pulam escadas, descem corrimãos, mesmo sabendo que, para elas, por sua natureza, a dor pode ser maior. $\mathrm{O}$ amor ao esporte não tem sexo (100\%SkateGirl, 2001:6).

O discurso das diferenças biológicas entre homens $e$ mulheres como demarcadores da sua participação nos esportes também está presente nesse editorial, mesmo que o autor tente relativizar essa representação, pois, ao mesmo tempo em que reconhece que o preconceito existe, recua e explicita que as skatistas, em decorrência da sua "natureza", são mais sensíveis à dor. Por isso "pagam um preço pela escolha que fazem" (Muraro, 2002:7), tendo que aguentar ironias e provocações, além de terem que provar para os organizadores dos campeonatos que são capazes de competir.

Justificativas como essas estão atravessadas por relações de poder, pois é a partir do referente (masculino) que o feminino é 
designado como mais frágil ou, nesse caso, mais sensível à dor. $\mathrm{Na}$ lógica dessa relação binária está implícita, ainda, uma hierarquização de atributos cujo polo positivo encontra-se fixado no forte, o que implica dizer, no masculino. Lembremos com Foucault, que

[...] nas relações humanas, há todo um feixe de relações de poder, que podem se exercer entre os indivíduos, no seio de uma família, em uma relação pedagógica, no corpo político. Esta análise das relações de poder constitui um campo extremamente complexo. Encontra, às vezes, o que podemos chamar fatos, ou estados de dominação, nos quais as relações de poder, em lugar de serem móveis e de permitir aos diferentes parceiros uma estratégia que as modifique, encontram-se bloqueadas e fixas. Quando um indivíduo ou um grupo social consegue bloquear um campo de relações de poder, a torná-las imóveis e fixas e a impedir uma reversibilidade do movimento [...] estamos diante do que se pode chamar de estado de dominação (2003:71-72).

A naturalização das relações entre o feminino e o masculino pautadas na ordem do biológico, expresso pela aparência e pela genitália do corpo, cria esse tipo de "estado de dominação":

As desigualdades encontram-se, deste modo, fundadas num discurso de 'evidência', ocultando-se, desta forma, que a própria ideia de diferença pressupõe todo um aparato valorativo, onde o sexo biológico é tomado como parâmetro principal na classificação do humano (Swain, 2004:4).

Se a ordem de gênero vigente toma o feminino como mais frágil em relação ao masculino, a referência que as skatistas fazem às dificuldades de se fazerem visíveis só pode ser entendida quando associada a uma representação de feminilidade que valoriza a fragilidade, a graciosidade, a delicadeza, percebendo-a, inclusive, como algo fixo, uniforme e coeso; algo intrinsecamente contido ou implicado na natureza do ser mulher. 
"Quando você é excluída, você faz o seu"

Essa visão é desconstruída pelo feminismo pós-estruturalista, ao considerar o gênero como algo que faz parte do sujeito e que o constitui (Swain, 2004; Louro, 1997). Para esse campo de estudo,

\begin{abstract}
masculinidade e feminilidade se definem reciprocamente visto não existir nenhuma essência a priori determinada para uma e outra identidade. Essas identidades, ao contrário, são produzidas na cultura não havendo uma fixidez na sua produção (Goellner, 2007:175).
\end{abstract}

Ou seja, cada sociedade ou grupo social estabelece essas relações que não são permanentes nem imanentes; são cambiantes, mutáveis. O que hoje é identificado como algo relacionado ao masculino pode ter sido diferente outrora, ou assim poderá vir a ser.

Quando Alexandre Vianna, na reportagem intitulada Lugar de mulher é no skate, divulgada pelo site Terra Esporte, afirma que a evolução do skate feminino "desmistifica todo aquele rótulo de que esporte de ação só pode ser praticado por homens" (2004:2), a representação de masculinidade que aqui se impõe está em oposição a uma outra, a de feminilidade. Ambas operam com o discurso da oposição binária masculino/feminino, fixada a partir de uma essência e universalidade próprias em cada um dos polos. Nesse caso, se "constrói a igualdade de cada lado da oposição e oculta as múltiplas identificações entre os lados opostos" (Mariano, 2005:482). Essa fixidez é problematizada por Joan Scott (1995), que, ao proporcionar formas de pensar fora dessa polarização, explode com a hierarquização que se estabelece entre os polos $e$ "passa a operar com a pluralidade no interior de cada um desses polos, [contemplando] as cumplicidades e os conflitos que podem arranjar e desarranjar as relações sociais" (Louro, 2002:16).

Aproximando essa discussão do universo do skate feminino, é possível perceber que, quando as skatistas informam que imprimem nos seus gestos e suas manobras "graça e leveza" (Meduza, 2005:1), isso não significa afirmar que essas qualidades sejam naturalmente femininas ou exclusivamente das mulheres. 
Do mesmo modo, quando afirmam que estão dominando com agressividade as pistas, de forma alguma afirmam que por isso estejam se apropriando de habilidades que são naturalmente masculinas. Beleza e agressividade, por exemplo, são características e adjetivações que podem ser referidas para movimentos e manobras que sejam executadas por um atleta ou por uma atleta. Atribuir um significado fixo a elas só acontece porque é resultante de uma discursividade que as colocou em oposição. São, portanto, inventadas, constituídas historicamente através de múltiplos discursos que regulam, normatizam, instauram saberes e produzem verdades (Foucault, 1999).

Em uma entrevista para a seção $100 \%$ SkateGirl, a skatista Katiane Shishito desenvolveu argumentos que desestabilizam as verdades contidas nessas representações.

Não consigo ver o skate de uma forma separada, acho que skate é skate, tanto que não faço diferença de andar com meninos ou com meninas, para mim é a mesma coisa. Acho que o skatista que acerta uma manobra tem o mesmo prazer, sendo homem ou mulher, é indescritível. Então não crio conceitos sobre skate feminino ou masculino. É claro que as meninas começaram um pouco depois e estão desenvolvendo a confiança agora, se acostumando com a ideia de que são capazes, porque a própria sociedade tem mania de impor conceitos como "coisas de menino e coisas de menina". Acho que todo ser humano é dotado de capacidade de fazer aquilo que sente vontade e que realmente quer fazer. Acho que estamos indo pra esse caminho, de sermos mais livres de conceitos ou preconceitos. Não digo alheio, isso é bobagem, mas de nós mesmos acreditarmos na gente (100\%SkateGirl, 2005:97).

Seu aprendizado se deu junto com os garotos, o que a fez identificar que o prazer que se sente com a execução de uma boa manobra é indescritível tanto para eles quanto para elas. Ainda assim, reconhece que há um sistema de produção de 
determinados significados que tende a fixá-los como sendo "coisas de menino e coisas de menina". Para escapar dessa representação, recorre à capacidade que todo ser humano tem de fazer o que gosta, de exercer a liberdade, independentemente dos preconceitos, de ter autoconfiança e aprender a acreditar em si mesmo.

Discurso semelhante a esse aparece na voz da skatista Gabi que, ao falar sobre sua participação no esporte, afirma:

[...] eu quero e tenho o pensamento de andar igual ou melhor que os homens, não quero ser inferior e sim melhor, eu gosto da sensação de acertar uma manobra difícil [...] a melhor coisa que tem é ficar bem comigo mesma (100\%SkateGirl, 2005:98).

Por certo, a sensação de conquistar um objetivo resulta de um longo processo de aprendizagem, o que exigiu muito investimento sobre seu corpo e seus modos de agir, produzindo confiança $e$ bem-estar. Investimento esse que se dá para mulheres e homens, ainda que possam ser de formas diferenciadas.

Extrair o melhor de si faz parte do universo esportivo; é, aliás, sua condição de possibilidade. Coragem, determinação e ousadia são características que compõem o universo dos esportes radicais cujos/as atletas e praticantes as assimilam em maior ou menor grau. Tal apropriação não se dá por uma ordem de gênero, mas pelo nível de envolvimento e aspiração que cada um/a tem no âmbito da prática esportiva. Eliana Sosco, atleta profissional do skate, ao ser questionada sobre o medo de executar algumas manobras consideradas difíceis, assim responde: "Eu me esforço muito e não tenho medo, tenho coragem pra jogar as manobras. Penso: se cair, do chão não passa" (2006:77).

Ao evocar a coragem, toma para si a responsabilidade de fazer o melhor de si nas competições, eventos, sessions, exibições. Assim sucedeu com a manobra que executou e garantiu a primeira 
capa feminina da Revista $100 \%$ Skate. ${ }^{12}$ "Quando chegamos fiquei de cara a borda era muito grande, nunca tinha andado num pico parecido. Já era noite e eu tinha que pelo menos tentar descer [...] depois que criei coragem foi fácil" (Sosco, 2006:78).

Ser uma boa skatista requer domínio de técnicas e saberes específicos, em relação, por exemplo, às posições do corpo e a suas mudanças em cada manobra, o momento certo para executá-las, enfim, um aprendizado técnico que só é garantido através de infindáveis repetições e tentativas. Além disso, pressupõe aprimorar modos de relacionar-se consigo mesma, como acreditar que é capaz de executar e se jogar nas manobras, enfim, ter confiança em si. Não há dúvidas de que a confiança e o aprendizado não são integrantes do cotidiano das skatistas apenas. Também são dos skatistas.

Talvez seja a representação de que as skatistas sejam "atletas de segunda classe" que possibilita a ocorrência de situações nas quais os atletas são glorificados, nomeados, trazidos à lembrança, enquanto as atletas figuram (quando figuram) em segundo plano, conforme podemos perceber, por exemplo, na cobertura que a mídia especializada em skate fez de um importante campeonato internacional que aconteceu na Europa no ano de 2005.

Ao relatar as conquistas que o skate brasileiro teve nessa competição, o editor da revista $100 \%$ Skate assinou uma coluna denominada Dando Idéias, na qual registrou:

Sandro Dias Mineirinho foi o campeão do circuito europeu no vertical, Daniel Vieira alcançou o mesmo no street. De quebra, este foi ainda o primeiro brasileiro a

\footnotetext{
${ }^{12}$ Eliana Sosco foi a primeira mulher a aparecer na capa da Revista $100 \%$ Skate, na edição de número 100, publicada em julho de 2006. Essa aparição se deu em função da pressão que as skatistas fizeram para que a revista publicasse uma capa com uma skatista em ação. A segunda capa cuja imagem é de uma skatista foi publicada em março de 2010, na qual aparece Leticia Bufoni.
} 
"Quando você é excluída, você faz o seu"

vencer na Alemanha na sua modalidade. Não é pouca coisa (Muraro, 2005:114).

Nesse mesmo circuito também participou e obteve a conquista do título de Campeã Mundial do Vertical Feminino a atleta brasileira Karen Jones, única brasileira a conseguir essa vitória. No entanto seu nome sequer é mencionado. As conquistas mencionadas pelo editor são do skate brasileiro masculino - o referente.

Karen Jones, tão logo venceu o campeonato, enviou ao Skate para Meninas, por e-mail, uma matéria cujo título Campeã Mundial foi dado pela editora do site. Comemora a atleta:

Só mando notícias agora porque tem net aqui no campeonato, é a primeira vez que sento com calma na frente do computador. Falando especificamente do Vert Feminino rolou competição. Eu vim para correr com os caras [...] então foi muito melhor do que eu esperava. Andei de boa, acertei tudo, isso me deixou mais feliz! No final da session eu achava que tinha ganho (humilde né) haha mas não contava na certeza porque sabe como são as coisas nesses campeonatos, às vezes algum nome pesa mais que o skate [...] Foi a maior festa. Eu ganhei no feminino, o Mineirinho no masculino e o Daniel Vieira no street [...] só faltou o street feminino pra gente levar tudo (Jones, 2005:1).

Nesses dois excertos podemos evidenciar discursos que falam de um mesmo circuito $e$ das conquistas de um grupo específico - skatistas do Brasil. No entanto um deles negligencia a vitória da atleta brasileira que compete na categoria vertical feminino, mesmo que tenha, junto com o grupo citado, conquistado um título bastante significativo para o skate nacional. Aqui podemos pensar que Muraro, ao ignorar a participação e a conquista de Karen Jones no circuito europeu de 2005, está posicionando apenas uma representação hegemônica de atleta do skate - a do sexo masculino. 
Tenha ou não a atleta conseguido um feito na história do skate brasileiro (o título de Campeã Mundial), a naturalização de que as conquistas mais importantes são dos atletas homens é aqui reafirmada na relação de poder que o editor tem, de dizer quem deve estar presente no que foi por ele produzido para ser divulgado. Silenciar a respeito do esforço e do trabalho que a atleta imprimiu sobre si para chegar nessa posição faz parte dessa rede discursiva que afirma, entre outras verdades, que no Brasil não há número de atletas mulheres suficiente para participar dos campeonatos femininos; que as skatistas precisam ser mais profissionais; e que precisam se empenhar mais na realização de manobras de difícil execução. O silenciamento acerca da presença e da vitória de Karen Jones reforça a permanência da norma, desfavorecendo, de certo modo, o desenvolvimento do skate feminino no Brasil.

Talvez seja exatamente para contestar essa norma que as skatistas têm promovido diferentes ações, buscando potencializar o skate feminino no Brasil. Além das diversas estratégias que as skatistas têm desenvolvido no sentido de se fazerem ver, sua ação parece ter se alastrado, também, para a fissura de representações cristalizadas relacionadas à ordem dos gêneros no interior do esporte. Ao mostrarem que são capazes de disputar competições com grande exigência física e técnica (na modalidade vertical, por exemplo), evidenciam que o skate não tem sexo e se assim é representado é porque, no seu entorno, diferentes disputas estão em ação.

A reação a tal representação permite entender que a participação das mulheres no universo cultural do skate se produz através de diferentes discursos que, ora mais, ora menos, incentivam essa participação. A não linearidade dos discursos é que permite a reação. Afinal, como bem explicitou Foucault (1992), onde há poder, há resistência, e os sujeitos não são meros receptores dos discursos: reagem, negociam e disputam.

As diferentes ações protagonizadas pelas skatistas podem ser assim analisadas. Algumas são capturadas pelos discursos da 
"Quando você é excluída, você faz o seu"

oficialidade, outras, os contestam, recusam e produzem novos discursos. Afinal, existem múltiplas formas de ser skatista, assim como existem múltiplas formas de produzir e reproduzir os discursos que circulam acerca da sua inserção nesse esporte, inclusive, acerca das relações de gênero.

\section{Referências bibliográficas}

100\%SKATEGIRL (1). Editorial. São Paulo, 2001, pp.6-7.

100\%SKATEGIRL (10) 81. São Paulo, 2005, pp.97-101.

ADELMAN, Miriam. Mulheres no esporte: corporalidades e subjetividades. Movimento (12) 1, Porto Alegre, 2006, pp.11-20.

BITENCOURT, Valéria et al. Esportes radicais e de aventura. In: DA COSTA, Lamartine (org.). Atlas do esporte no Brasil: atlas do esporte, educação física, e atividades físicas de saúde e lazer no Brasil. Rio de Janeiro, Shape, 2005, pp.409-421.

BRITTO, Eduardo. A onda dura: 3 décadas de skate no Brasil. São Paulo, Gráfica Círculo, 2000.

Como Surgimos, Blog Unidas pelo Carrinho, São Paulo, 2002. Disponível em: http://unidaspelocarinho.weblogger.terra.com.br/index.htm. Acesso em: 14 mar. 2004.

Foucault, Michel. Microfísica do poder. Rio de Janeiro, Edições Graal, 1992.

. Ditos \& Escritos, vol. IV. Estratégia, Poder-Saber. Rio de Janeiro, Forense Universitária, 2003.

- A arqueologia do saber. Rio de Janeiro, Forense Universitária, 2005.

GINZBURG, Carlo. Mitos, emblemas, sinais: morfologia e história. São Paulo, Companhia das Letras, 2003.

GoElLnER, Silvana V. Feminismos, mulheres e esportes: questões epistemológicas sobre o fazer historiográfico. Movimento (13) 2, Porto Alegre, 2007, pp.171-196. 
HALL, Stuart. Identidade cultural na pós-modernidade. Rio de Janeiro, DP\&A, 1997.

IULIANELLI, Jorge A. Juventude: construindo processos - o protagonismo juvenil. In: PONTES, Paulo C. e IULiANELLI, Jorge. A. (Orgs.). Jovens em tempo real. Rio de Janeiro, DP\&A, 2003, pp.37-42.

JONES, Karen. Campeã Mundial. Skate para Meninas, 2005. Disponível em: $<$ http://www.skateparameninas.com.br>. Acesso em: 15 set. 2009.

LEINE, Evelyn. Entrevista com Patiane Freitas. Skate para Meninas, 2004. Disponível em: <http://www.skateparameninas.com.br>. Acesso em: 12 maio 2009.

. Quase uma tour no interior. Skate para Meninas, 2005. Disponível em: <http://www.skateparameninas.com.br>. Acesso em: 15 set. 2009.

LOURO, Guacira L. Gênero, sexualidade e educação: uma perspectiva pós-estruturalista. Petrópolis, Vozes, 1997.

. Epistemologia feminista e teorização social - desafios, subversões e alianças. In: ADELMAN, Miriam e SILVESTRIN, Celsi B. (Orgs). Gênero Plural: um debate interdisciplinar. Curitiba, Editora UFPR, 2002, pp.11-22.

. Currículo, gênero e sexualidade - o "normal", o "diferente" e o "excêntrico". In: LOURO, Guacira; GoELLNER, Silvana; e FELIPE, Jane. Corpo, gênero e sexualidade: um debate contemporâneo na educação. Petrópolis, Vozes, 2010, pp.41-52.

MARIANO, Silvana A. O sujeito do feminismo e o pós-estruturalismo. Revista Estudos Feministas (13) 3, Florianópolis, 2005, pp.483-505.

MEDUZA, Alessandra. $1^{\circ}$ Encontro Unidas pelo Carrinho. Skate para Meninas, 2005. Disponível em: <http://skateparameninas.com.br>. Acesso em: 21 dez. 2009.

MEYER, Dagmar E. E. Gênero e saúde: indagações a partir do pósestruturalismo e dos estudos culturais. Revista de Ciências da Saúde (17) 1, Florianópolis, 1998, pp.13-32.

MuRARO, Cauê. Está por conta delas. Editorial. Encarte 100\%Skate Girl (1), São Paulo, 2001, pp.7-8. 
"Quando você é excluída, você faz o seu"

. Dando Idéias. 100\%Skate (81), São Paulo, 2005, pp.97-101. pp.6-8. . Editorial. Encarte 100\%Skate Girl (2). São Paulo, 2002,

REVEL, Judith. Foucault: conceitos essenciais. São Paulo, Claraluz, 2005.

ScotT, Joan. Gênero: uma categoria útil de análise histórica. Educação \& Realidade (20) 2, Porto Alegre, 1995, pp.71-100.

Sosco, Eliana. Eliana Sosco prá quem subestimou a capacidade delas. Revista 100\%Skate (100), São Paulo, 2006, pp.76-79.

SWAIN, Tânia N. Os limites discursivos da história: imposição de sentidos. Labrys: estudos feministas (9), Brasília, 2006. Disponível em: <http://www.unb.br:80/ih/his/gefem/labrys9/libre/anahita.htm>. Acesso em: 3 dez. 2010.

ViAnNA, Alexandre. Lugar de mulher é no skate. Terra Esporte. São Paulo, 2004. Disponível em: $<$ http://virgula.terra.com.br/esporte/thps/interna.php?id=3481 > . Acesso em: 5 dez 2010. 